\title{
Persistence in the cryptocurrency market
}

\author{
Guglielmo Maria Caporale ${ }^{\mathrm{a}, \mathrm{b}, *}$, Luis Gil-Alana $^{\mathrm{c}}$, Alex Plastun $^{\mathrm{d}}$

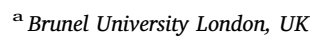 \\ ${ }^{\mathrm{b}}$ CESifo and DIW, Berlin, Germany \\ ${ }^{\mathrm{c}}$ University of Navarra, Spain \\ ${ }^{\mathrm{d}}$ Sumy State University, Ukraine
}

\section{A R T I C L E I N F O}

\section{Keywords:}

Crypto currency

BitCoin

Persistence

Long memory

R/S analysis

Fractional integration

JEL classification:

C22

G12

\begin{abstract}
A B S T R A C T
This paper examines persistence in the cryptocurrency market. Two different long-memory methods (R/S analysis and fractional integration) are used to analyse it in the case of the four main cryptocurrencies (BitCoin, LiteCoin, Ripple, Dash) over the sample period 2013-2017. The findings indicate that this market exhibits persistence (there is a positive correlation between its past and future values), and that its degree changes over time. Such predictability represents evidence of market inefficiency: trend trading strategies can be used to generate abnormal profits in the cryptocurrency market.
\end{abstract}

\section{Introduction}

The exponential growth of BitCoin and other cryptocurrencies is a phenomenon that has attracted considerable attention in recent years. The cryptocurrency market is rather young (BitCoin was created in 2009, but active trade only started in 2013) and therefore still mostly unexplored (see Caporale and Plastun, 2017 for one of the very few existing studies, with a focus on calendar anomalies). One of the key issues yet to be analysed is whether the dynamic behaviour of cryptocurrencies is predictable, which would be inconsistent with the Efficient Market Hypothesis (EMH), according to which prices should follow a random walk (see Fama, 1970). Long-memory techniques can be applied for this purpose. Several studies have provided evidence of persistence in asset price dynamics (see Greene and Fielitz, 1977; Caporale et al., 2016), and also found that this changes over time (see Lo, 1991), but virtually none has focused on the cryptocurrency market. One of the few exceptions is due to Bouri et al. (2016), who find lon- memory properties in the volatility of Bitcoin.

The present study carries out a more comprehensive analysis by considering four main cryptocurrencies (the most liquid ones: BitCoin, LiteCoin, Ripple, Dash) and applying two different long-memory methods (R/S analysis and fractional integration) over the period 2013-2017 to investigate their stochastic properties. Moreover, it also examines the evolution of persistence over time (by looking at changes in the Hurst exponent). Any predictable patterns could of course be used as a basis for trading strategies aimed at making abnormal profits in the cryptocurrency market.

The layout of the paper is the following. Section 2 provides a brief review of the relevant literature. Section 3 describes the data and outlines the empirical methodology. Section 4 presents the empirical results. Section 5 provides some concluding remarks.

\footnotetext{
* Corresponding author at: Department of Economics and Finance, Brunel University, London, UB8 3PH, UK.

E-mail address: Guglielmo-Maria.Caporale@brunel.ac.uk (G.M. Caporale).
} 
Table 1

Capitalisation of the cryptocurrency market (27.10.2017).

Source: https://coinmarketcap.com/coins/.

\begin{tabular}{|c|c|c|c|c|c|}
\hline$\#$ & Name & Market Cap & Price & Circulating Supply & Data starts from \\
\hline 1 & Bitcoin & $\$ 98035067124$ & $\$ 5888.16$ & 16649525 ВTC & 28 Apr 2013 \\
\hline 2 & Ethereum & $\$ 28411539142$ & $\$ 297.97$ & $95350974 \mathrm{ETH}$ & 07 Aug 2015 \\
\hline 3 & Ripple & $\$ 7825254645$ & $\$ 0.203087$ & 38531538922 XRP & 04 Aug 2013 \\
\hline 4 & Bitcoin Cash & $\$ 5928832364$ & $\$ 354.52$ & 16723313 BCEH & $23 \mathrm{Jul} 2017$ \\
\hline 5 & Litecoin & $\$ 2974020034$ & $\$ 55.53$ & 53556032 LTC & 28 Apr 2013 \\
\hline 6 & Dash & $\$ 2179887702$ & $\$ 285.10$ & 7646019 DASH & 14 Feb 2014 \\
\hline 7 & NEM & $\$ 1786032000$ & $\$ 0.198448$ & 8999999 XEM & 01 Apr 2015 \\
\hline 8 & BitConnect & $\$ 1582408231$ & $\$ 216.50$ & 7308910 BCEC & 20 Jan 2017 \\
\hline 9 & NEO & $\$ 1429555000$ & $\$ 28.59$ & $50000 \mathrm{NEO} *$ & 09 Sept 2016 \\
\hline 10 & Monero & $\$ 1331970304$ & $\$ 87.21$ & $15273032 \mathrm{XMR}$ & 21 May 2014 \\
\hline
\end{tabular}

Cryptocurrency Market Capitalisation. Data.

\section{Literature review}

As already mentioned above, the cryptocurrency market has only been in existence for a few years, and therefore only a handful of studies have been carried out. ElBahrawy et al. (2017) provide a comprehensive analysis of 1469 cryptocurrencies considering various issues such as market shares and turnover. Cheung et al. (2015), Dwyer (2014), Bouoiyour and Selmi (2015) and Carrick (2016) show that this market is much more volatile than others. Halaburda and Gandal (2014) analyse its degree of competitiveness Urquhart (2016) and Bartos (2015) focus on efficiency finding evidence for and against respectively. Anomalies in the cryptocurrency market are examined by Kurihara and Fukushima (2017) and Caporale and Plastun (2017).

Bariviera et al. (2017) test the presence of long memory in the Bitcoin series from 2011 to 2017. They find that the Hurst exponent changes significantly during the first years of existence of Bitcoin before becoming more stable in recent times. Bariviera (2017) also use the Hurst exponent and detect long memory in the daily dynamics of BitCoin as well as its volatility; in addition, they find more evidence of informational efficiency since 2014. Bouri et al. (2016) examine persistence in the level and volatility of Bitcoin using both parametric and semiparametric techniques; they detect long memory in both measures of volatility considered (absolute and squared returns). Catania and Grassi (2017) provide further evidence of long memory in the cryptocurrency market, whilst Urquhart (2016) using the R/S Hurst exponent obtains strong evidence of anti-persistence, which indicates non-randomness of Bitcoin returns.

\section{Data and methodology}

We focus on the four cryptocurrencies with the highest market capitalisation and longest span of data (see Table 1 below): BitCoin, LiteCoin, Ripple and Dash. The frequency is daily, and the data source is CoinMarketCap (https://coinmarketcap.com/coins/ ).

The two approaches followed are R/S analysis and fractional integration respectively. The following algorithm is used for the R/S analysis (see Mynhardt et al., 2014 for additional details):

1. A time series of length $M$ is transformed into one of length $N=M-1$ using logs and converting prices into returns:

$$
N_{i}=\log \left(\frac{Y_{t+1}}{Y_{t}}\right), \quad t=1,2,3, \ldots(M-1)
$$

2. This period is divided into contiguous $A$ sub-periods with length $\mathrm{n}$, such that $A_{n}=N$, then each sub-period is identified as $I_{a}$, given the fact that $a=1,2,3$., A. Each element $I_{a}$ is represented as $N_{k}$ with $k=1,2,3 ., N$. For each $I_{a}$ with length $n$ the average $e_{a}$ is defined as:

$$
\mathrm{e}_{\mathrm{a}} \frac{1}{\mathrm{n}} \sum_{\mathrm{k}=1}^{\mathrm{n}} \mathrm{N}_{\mathrm{k}, \mathrm{a}}, \mathrm{k}=1,2,3 \ldots . \mathrm{N}, \mathrm{a}=1,2,3 \ldots, \mathrm{A}
$$

Table 2

Results of the R/S analysis for the different crypto currencies, 2014-2017.

\begin{tabular}{ll}
\hline Period & Daily frequency \\
\hline Bitcoin & 0.59 \\
LiteCoin & 0.63 \\
Ripple & 0.64 \\
Dash & 0.60 \\
\hline
\end{tabular}


Bitcoin

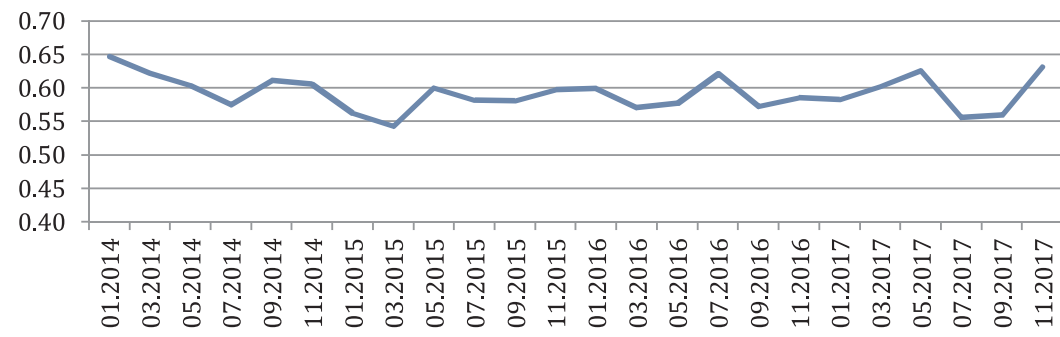

Litecoin

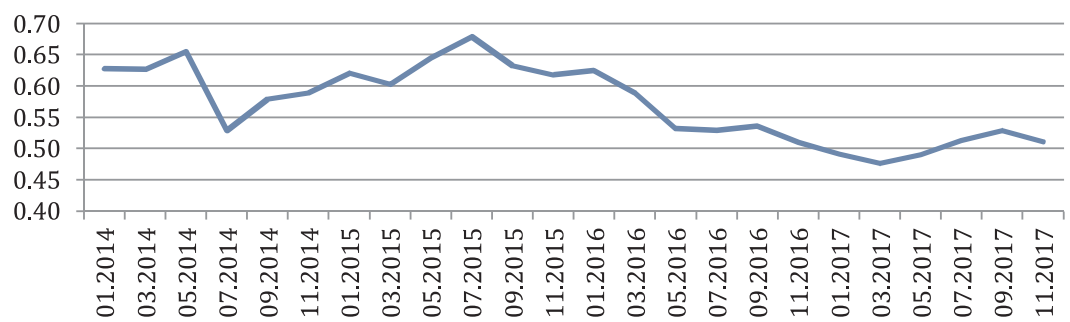

Ripple

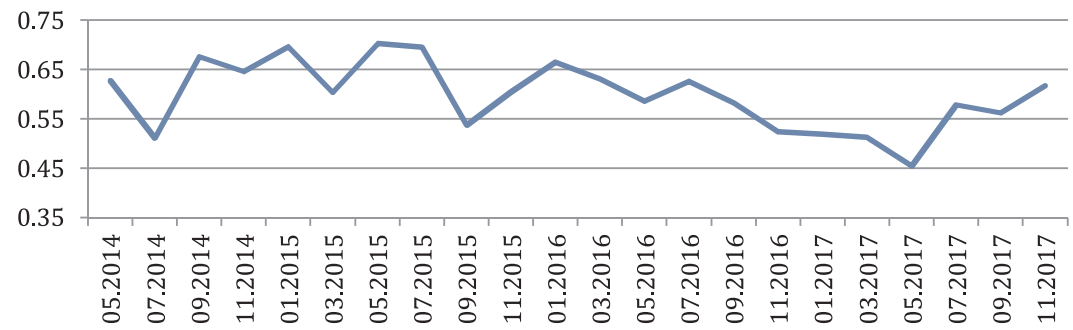

Dash

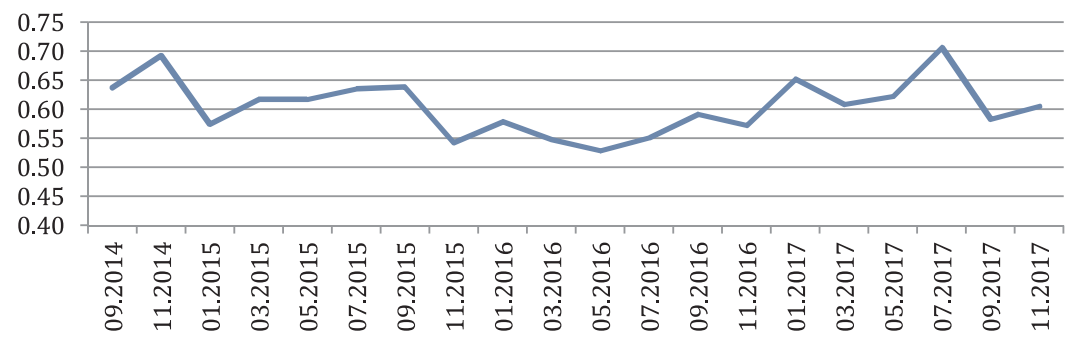

Fig. 1. Results of the dynamic $\mathrm{R} / \mathrm{S}$ analysis, $(\mathrm{step}=50$, data window $=300$ ).

Table 3

Estimates of $\mathrm{d}$ and confidence bands for the case of no autocorrelation.

\begin{tabular}{|c|c|c|c|}
\hline Log series & No terms & An intercept & A linear time trend \\
\hline BITCOIN & $0.992(0.961,1.040)$ & $1.009(0.983,1.039)$ & $1.009(0.983,1.039)$ \\
\hline LITECOIN & $1.005(0.977,1.038)$ & $1.021(0.994,1.053)$ & $1.021(0.994,1.053)$ \\
\hline RIPPLE & $1.028(0.997,1.064)$ & $1.053(1.023,1.086)$ & $1.053(1.023,1.087)$ \\
\hline DASH & $0.966(0.933,1.005)$ & $0.985(0.954,1.022)$ & $0.986(0.954,1.022)$ \\
\hline
\end{tabular}


Table 4

Estimated coefficients in the selected models from Table 3.

\begin{tabular}{lll}
\hline Log series & $\mathrm{d}(95 \%$ band $)$ & Intercept \\
\hline BITCOIN & $1.009(0.983,1.039)$ & $4.897(114.15)$ \\
LITECOIN & $1.021(0.994,1.053)$ & $1.470(21.60)$ \\
RIPPLE & $1.053(1.023,1.086)$ & $-5.313(-66.89)$ \\
DASH & $0.986(0.954,1.022)$ & $-0.984(-11.37)$ \\
\hline
\end{tabular}

Table 5

Estimates of $\mathrm{d}$ and confidence bands for the case of autocorrelation.

\begin{tabular}{|c|c|c|c|}
\hline Log series & No terms & An intercept & A linear time trend \\
\hline BITCOIN & $0.962(0.920,1.013)$ & $1.031(0.988,1.074)$ & $1.032(0.988,1.074)$ \\
\hline LITECOIN & $0.983(0.944,1.030)$ & $1.016(0.972,1.064)$ & $1.016(0.972,1.064)$ \\
\hline RIPPLE & $1.048(0.991,1.113)$ & $1.052(1.012,1.110)$ & $1.052(1.012,1.110)$ \\
\hline DASH & $0.911(0.8733,0.953)$ & $0.963(0.920,1.013)$ & $0.963(0.920,1.013)$ \\
\hline
\end{tabular}

Table 6

Estimated coefficients in the selected models from Table 5.

\begin{tabular}{|c|c|c|c|}
\hline Log series & d (95\% band) & Intercept & Time trend \\
\hline BITCOIN & $1.032(0.988,1.074)$ & $4.897(114.23)$ & $0.002(1.73)$ \\
\hline LITECOIN & $1.016(0.972,1.064)$ & $1.470(21.56)$ & - \\
\hline RIPPLE & $1.052(1.012,1.110)$ & $-5.131(-66.84)$ & - \\
\hline DASH & $0.963(0.920,1.013)$ & $-0.977(-11.30)$ & $0.004(2.68)$ \\
\hline
\end{tabular}

Table 7

Estimates of d based on a semiparametric Whittle method.

\begin{tabular}{llllllllllll}
\hline Log series & 30 & 32 & 34 & 36 & 38 & 40 & 42 & 44 & 46 & & \\
\hline BITCOIN & 1.072 & 1.099 & 1.078 & 1.081 & 1.108 & $\mathbf{1 . 1 4 2}$ & $\mathbf{1 . 1 5 2}$ & 1.109 & $\mathbf{1 . 1 8 6}$ & 1.107 & 1.100 \\
LITECOIN & 1.123 & $\mathbf{1 . 1 7 3}$ & 1.096 & 1.125 & $\mathbf{1 . 1 4 1}$ & $\mathbf{1 . 1 7 4}$ & $\mathbf{1 . 1 2 2}$ & 1.101 & 1.101 & 1.103 & 1.076 \\
RIPPLE & $\mathbf{1 . 1 5 3}$ & 1.091 & 1.125 & $\mathbf{1 . 1 3 7}$ & 1.096 & 1.088 & 1.064 & 1.042 & 1.047 & 1.011 & 1.022 \\
DASH & $\mathbf{1 . 1 7 0}$ & 1.081 & $\mathbf{1 . 1 5 0}$ & $\mathbf{1 . 2 0 0}$ & $\mathbf{1 . 2 3 5}$ & $\mathbf{1 . 2 2 8}$ & $\mathbf{1 . 2 1 6}$ & $\mathbf{1 . 2 0 2}$ & $\mathbf{1 . 1 5 4}$ & $\mathbf{1 . 1 4 5}$ & $\mathbf{1 . 1 6 2}$ \\
Lower I(1) & 1.150 & 1.145 & 1.141 & 1.137 & 1.133 & 1.130 & 1.126 & 1.124 & 1.121 & 1.118 & 1.114 \\
Upper I(1) & 0.849 & 0.854 & 0.858 & 0.862 & 0.866 & 0.869 & 0.873 & 0.876 & 0.878 & 0.881 & 0.883 \\
\hline
\end{tabular}

In bold those cases where the estimates of $d$ are significantly higher than 1 at the $5 \%$ level.

3. Accumulated deviations $X_{k, a}$ from the average $e_{a}$ for each sub-period $I_{a}$ are defined as:

$$
(R / S)_{n}=(1 / A) \sum_{i=1}^{A}\left(R_{I a} / S_{I a}\right)
$$

The range is defined as the maximum index $X_{k, a}$ minus the minimum $X_{k, a}$, within each sub-period $\left(I_{a}\right)$ :

$$
R_{I a}=\max \left(X_{k, a}\right)-\min \left(X_{k, a}\right), \quad 1 \leq k \leq n .
$$

4. The standard deviation $S_{I a}$ is calculated for each sub-period $I_{a}$ :

$$
S_{I a}=\left(\left(\frac{1}{n}\right) \sum_{k=1}^{n}\left(N_{k, a}-e_{a}\right)^{2}\right)^{0,5}
$$

5. Each range $R_{I a}$ is normalised by dividing by the corresponding $S_{I a}$. Therefore, the re-normalised scale during each sub-period $I_{a}$ is $R_{I a} / S_{I a}$. In step 2 above, adjacent sub-periods of length $\mathrm{n}$ are obtained. Thus, the average $\mathrm{R} / \mathrm{S}$ for length $n$ is defined as:

6. The length $n$ is increased to the next higher level, $(M-1) / n$, and must be an integer number. In this case, $n$-indexes that include the start and end points of the time series are used, and Steps $1-6$ are repeated until $n=(M-1) / 2$.

7. The least square method is used to estimate the equation $\log (R / S)=\log (c)+H * \log (n)$. The slope of the regression line is an estimate of the Hurst exponent $H$. (Hurst, 1951). 
Bitcoin

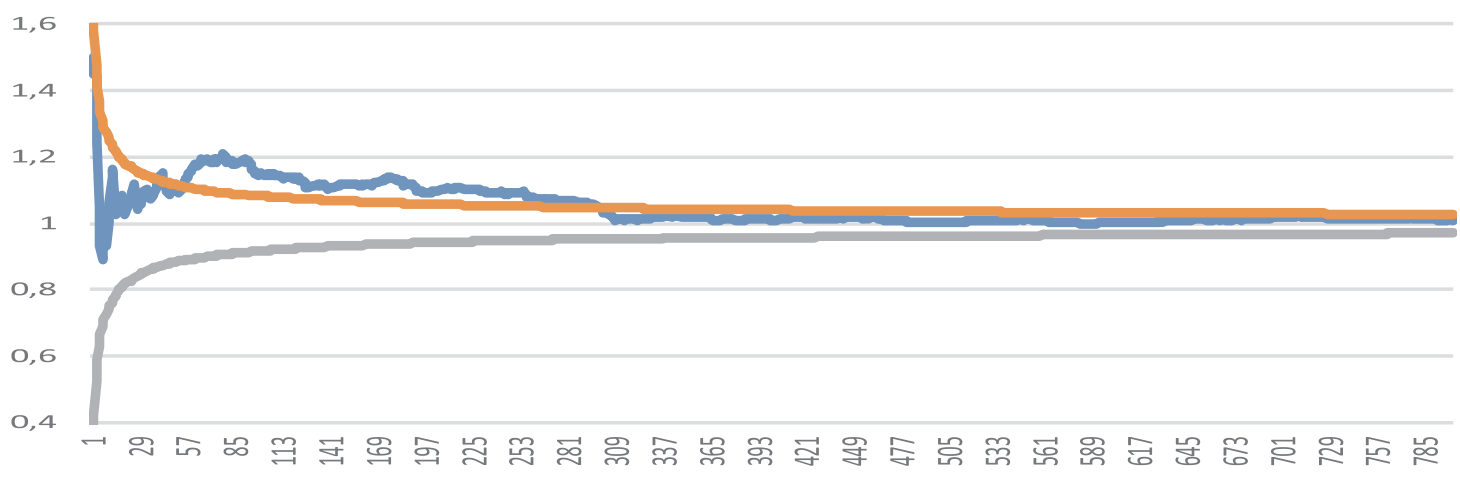

\section{Litecoin}

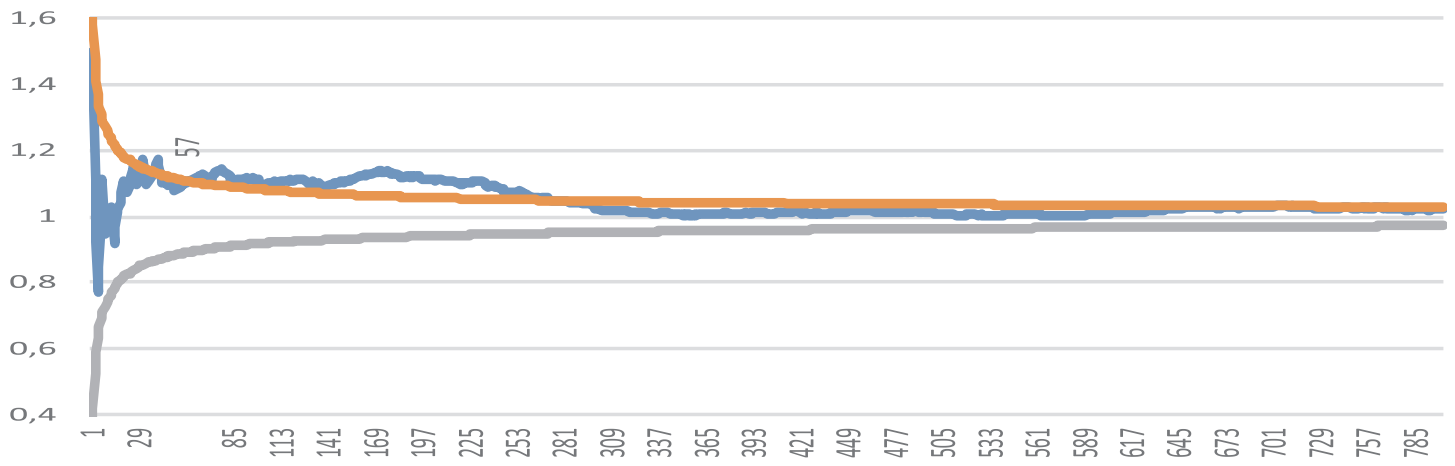

Ripple

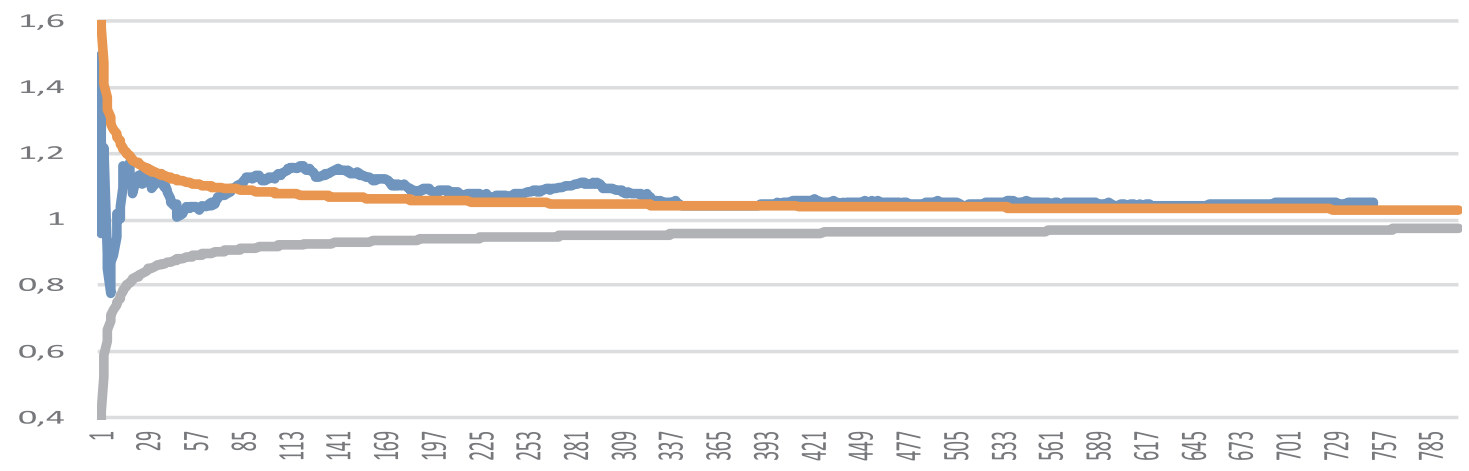

Dash

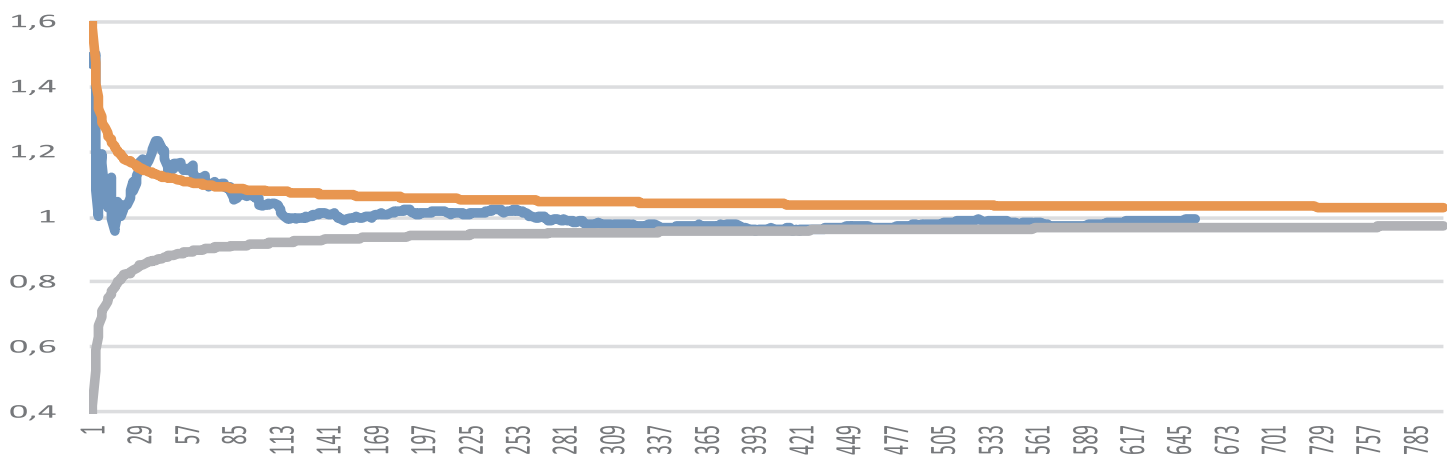


Fig. 2. Estimates of $d$ based on semiparametric methods.

$$
X_{k, a}=\sum_{i=1}^{k}\left(N_{i, a}-e_{a}\right)
$$

The Hurst exponent lies in the interval [0,1]. On the basis of the $\mathrm{H}$ values three categories can be identified: the series are antipersistent, returns are negatively correlated $(0 \leq \mathrm{H}<0.5)$; the series are random, returns are uncorrelated, there is no memory in the series $(\mathrm{H}=0.5)$; the series are persistent, returns are highly correlated, there is memory in price dynamics $(0.5<\mathrm{H} \leq 1)$.

To analyse the dynamics of market persistence we use a sliding-window approach. The procedure is the following: having obtained the first value of the Hurst exponent (for example, for the date 01.04.2004 using data for the period from 01.01 .2004 to 31.03.2004), each of the following ones is calculated by shifting forward the "data window", where the size of the shift depends on the number of observations and a sufficient number of estimates is required to analyse the time-varying behaviour of the Hurst exponent. For example, if the shift equals 10, the second value is calculated for 10.04 .2004 and characterises the market over the period 10.01.2004 till 09.04.2004, and so on.

In addition we also employ I(d) techniques for the log prices series, both parametric and semiparametric. Note that the differencing parameter $\mathrm{d}$ is related to the Hurst exponential described above through the relationship $\mathrm{H}=\mathrm{d}+0.5$. Also, $\mathrm{R} / \mathrm{S}$ analysis is used for the return series (the first differences of the log prices), while I(d) models are estimated for the log prices themselves, in which case the relationship becomes $\mathrm{H}=(\mathrm{d}-1)+0.5=\mathrm{d}-0.5$. We consider processes of the form:

$$
(1-B)^{d} x_{t}=u_{t}, \quad t=1,2, \ldots,
$$

where $\mathrm{B}$ is the backshift operator $\left(\mathrm{Bx}_{\mathrm{t}}=\mathrm{x}_{\mathrm{t}-1}\right) ; \mathrm{u}_{\mathrm{t}}$ is an $\mathrm{I}(0)$ process (which may incorporate weak autocorrelation of the AR(MA) form) and, $\mathrm{x}_{\mathrm{t}}$ are the errors of a regression model of the form:

$$
\mathrm{y}_{\mathrm{t}}=\beta_{0}+\beta_{1} t+x_{\mathrm{t}} ; \quad t=1,2, \ldots,
$$

where $y_{t}$ stands for the log price of each of the cryptocurrencies. Note that under the Efficient Market Hypothesis the value of $d$ in (7) should be equal to 1 and $u_{t}$ a white noise process. As mentioned before, we use both parametric and semiparametric methods, in each case assuming uncorrelated (white noise) and autocorrelated errors in turn. More specifically, we use first the Whittle estimator of $d$ in the frequency domain (Dahlhaus, 1989; Robinson, 1994), and then the "local" Whittle estimator initially proposed by Robinson (1995) and then further developed by Velasco (1999), Phillips and Shimotsu (2005), Abadir et al. (2007) and others.

\section{Empirical results}

The results of the R/S analysis for the return series of the four cryptocurrencies are presented in Table 2 .

As can be seen, the series do not follow a random walk, and are persistent, which is inconsistent with market efficiency. The most efficient cryptocurrency is Bitcoin, which is the oldest and most commonly used, as well as the most liquid.

The dynamic R/S analysis shows the evolution over time of persistence in the cryptocurrency market (see Fig. 1).

As can be seen the degree of persistence varies over the time, and fluctuates around its average. Time variation is particularly evident in the case of Litecoin, with the exponent dropping significantly from 0.7 in 2015-0.50 in 2017 . This represents evidence in favour of the Adaptive Market Hypothesis (see Lo, 1991 for details) and also of efficiency increasing over time. In the case of Litecoin the market was initially rather inefficient, but after 2-3 years it became more liquid, and the number of participants, trade volumes and efficiency all increased.

Next we estimate an I(d) model specified as:

$$
y_{t}=\alpha+\beta t+x_{t}, \quad(1-B)^{d} x_{t}=u_{t}, \quad t=1,2, \ldots,
$$

and test the null hypothesis:

$$
H_{o}: \quad d=d_{o},
$$

in (9) for $\mathrm{d}_{\mathrm{o}}$-values equal to $-1,-0.99, \ldots .-0.01,0,0.01, \ldots, 0.99$ and 1 under different modelling assumptions for the $\mathrm{I}(0)$ error term $\mathrm{u}_{\mathrm{t}}$.

In Table 3 we assume that $u_{t}$ in (1) is a white noise process, and consider the three cases of: i) no deterministic terms, ii) an intercept, and iii) an intercept with a linear time trend. This table shows that the estimates are around 1 in all cases, which implies non-stationary behaviour. A time trend is required in the cases of Bitcoin and Dash, but not for the other two series, Litecoin and Ripple.

Finally Table 4 (which focuses on the selected model for each series on the basis of the deterministic terms) shows that the I(1) hypothesis cannot be rejected for three series, namely Bitcoin, Litecoin and Dash. However, for Ripple it is rejected in favour of $\mathrm{d}>1$. The implied values of the $\mathrm{H}$ exponent are slightly smaller than those reported before: since $\mathrm{H}=\mathrm{d}-0.5$, they are $0.51,0.52$, 0.53 and 0.48 respectively for Bitcoin, Litecoin, Ripple and Dash, and the confidence intervals provide evidence of market inefficiency only in the case of Ripple.

Next we allow for autocorrelated disturbances, and for this purpose we use the exponential spectral model of Bloomfield (see Bloomfield, 1973 for details). Table 5 displays the estimates of $\mathrm{d}$ for the three cases of no regressors, an intercept and a linear time 


\section{Bitcoin}
1,3
1,2
1,1
1
9
0,8
0,7

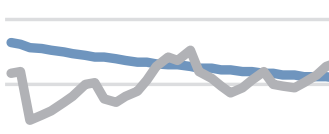

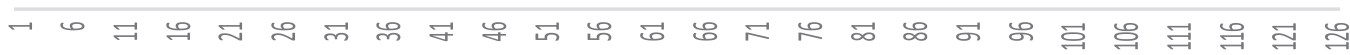

\section{Litecoin}

1,2

1,15

1,1

1,05

1

0,95

0,9

0,85

0,8

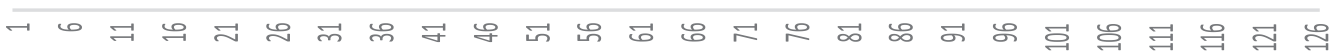

Ripple

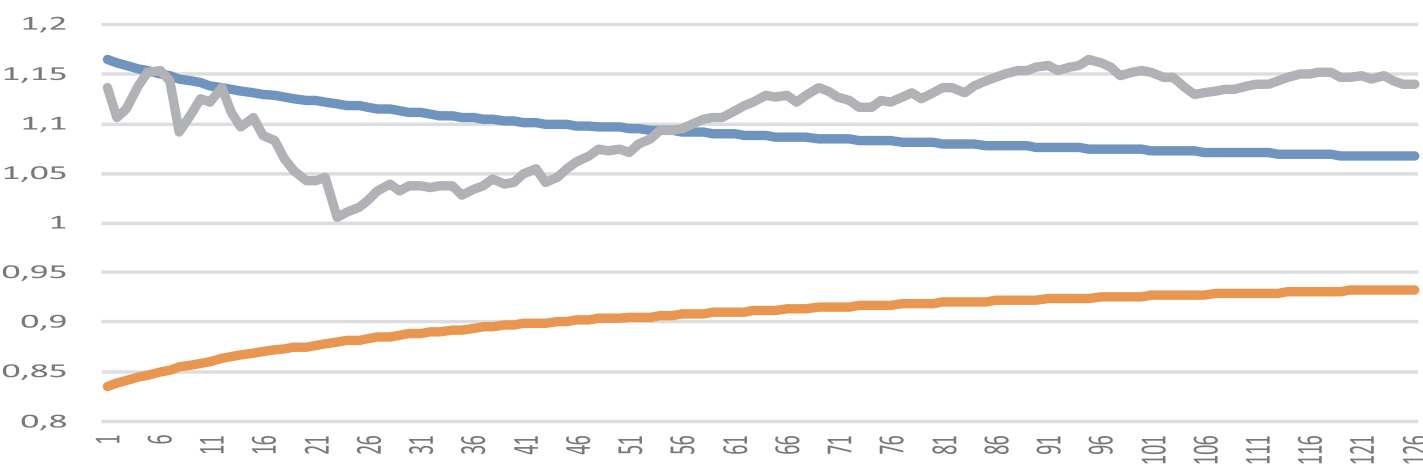

Dash

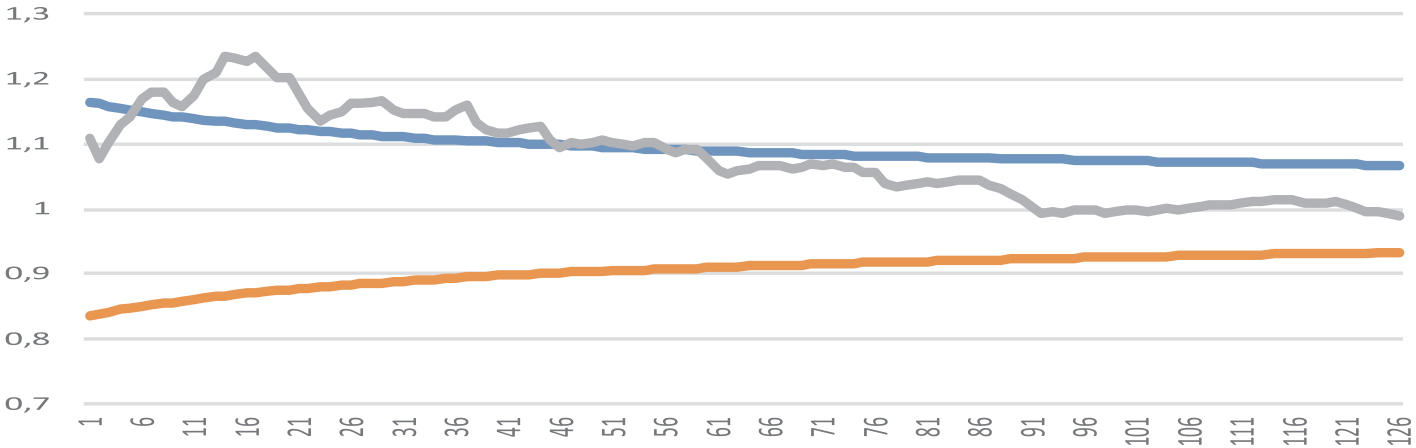

Fig. 3. Estimates of $d$ based on semiparametric methods (with $\mathrm{m}=25, \ldots, 200$ ). 
trend while Table 6 focuses on the selected models. As in the case of uncorrelated errors, a time trend is required for Bitcoin and Dash but not for the other two series. As before, the estimates of $d$ are within the I(1) interval for all series except Ripple, for which the estimate of $\mathrm{d}$ is significantly higher than 1 , which implies a high degree of persistence.

Given the differences between the results from the (non-parametric) R/S analysis and the parametric I(d) estimation, we also employ a semiparametric I(d) method, namely a "local" Whittle estimator in the frequency domain (see Robinson, 1995, etc.). The estimates for selected bandwidth parameters are shown in Table $7 .^{1}$

The unit root hypothesis (i.e., $\mathrm{d}=1$ ) is rejected in many cases, especially for Dash, but also for the other three series.

Fig. 2 displays the estimates of $\mathrm{d}$ for all bandwidth parameters and Fig. 3 focuses on values of $\mathrm{m}$ from 25 to 200 .

Depending on the bandwidth parameters the estimates of $d$ are within the I(1) interval or above 1 . Therefore there is strong evidence that mean reversion does not occur, which suggests market inefficiency.

\section{Conclusions}

This paper uses R/S analysis and fractional integration long-memory techniques to examine the degree of persistence of the four main cryptocurrencies (BitCoin, LiteCoin, Ripple and Dash) and its evolution over time. In brief, the evidence suggests that the cryptocurrency market is still inefficient, but is becoming less so. This is especially true of the Litecoin market, where the Hurst exponent dropped considerably over time.

The results obtained using I(d) methods are less conclusive, since the estimated values of d are higher than but not significantly different from 1 in a number of cases, the main exception being Ripple for which the parametric estimate of $d$ is significantly higher than 1 . The semiparametric I(d) results are very sensitive to the choice of the bandwidth parameter, and market inefficiency is found in a number of cases.

Persistence implies predictability, and therefore represents evidence of market inefficiency, suggesting that trend trading strategies can be used to generate abnormal profits in the cryptocurrency market.

\section{Acknowledgements}

Luis A. Gil-Alana gratefully acknowledges financial support from the Ministerio de Ciencia y Tecnología (ECO2014-55236). Alex Plastun gratefully acknowledges financial support from the Ministry of Education and Science of Ukraine (0117U003936). Comments from the Editor and an anonymous reviewer are gratefully acknowledged.

\section{References}

Abadir, K.M., Distaso, W., Giraitis, L., 2007. Nonstationarity-extended local whittle estimation. J. Econom. 141, $1353-1384$.

Bariviera, Aurelio F., María José, Basgall, Waldo, Hasperué, Marcelo, Naiouf, 2017. Some stylized facts of the Bitcoin market. Phys. A 484, 82-90.

Bariviera, Aurelio F., 2017. The inefficiency of bitcoin revisited: a dynamic approach. Econo. Lett. 161, 1-4.

Bartos, J., 2015. Does Bitcoin follow the hypothesis of efficient market? Int. J. Econ. Sci. 4 (2), 10-23.

Bloomfield, P., 1973. An exponential model in the spectrum of a scalar time series. Biometrika 60, 217-226.

Bouoiyour, Jamal, Selmi, Refk, 2015. Bitcoin Price: Is It Really That New Round of Volatility can Be on Way? MPRA Paper 65580. University Library of Munich, Germany. https://ideas.repec.org/p/pra/mprapa/65580.html.

Bouri, Elie, Georges, Azzi, Anne Haubo, Dyhrberg, 2016. On the Return-volatility Relationship in the Bitcoin Market Around the Price Crash of 2013. Economics Discussion Papers, No 2016-41. Kiel Institute for the World Economy. http://www.economics-ejournal.org/economics/discussionpapers/2016-41.

Caporale, Guglielmo Maria, Plastun, Oleksiy, 2017. The Day of the Week Effect in the Crypto Currency Market (October 20, 2017). Brunel University London, Department of Economics and Finance (Working Paper No. 17-19. Available at SSRN). https://ssrn.com/abstract $=3056229$.

Caporale, G.M., Gil-Alana, L.A., Plastun, A., Makarenko, I., 2016. Long memory in the Ukrainian stock market and financial crises. J. Econ. Finance 40 (2), 235-257. Carrick, J., 2016. Bitcoin as a complement to emerging market currencies. Emerg. Markets Finance Trade 52, 2321-2334.

Catania, LeopoldoGrassi, Stefano Modelling Crypto-Currencies Financial Time-Series (August 16, 2017) (Available at SSRN:). https://ssrn.com/abstract=3028486. Cheung, A., Roca, E., Su, J.-J., 2015. Crypto-currency bubbles: an application of the Phillips-Shi-Yu (2013) methodology on Mt. gox bitcoin prices. Appl. Econ. 47, $2348-2358$.

Dahlhaus, R., 1989. Efficient parameter estimation for self-similar process. Ann. Stat. 17, 1749-1766.

Dwyer, G.P., 2014. The economics of bitcoin and similar private digital currencies. J. Financ. Stab. 17, 81-91.

ElBahrawy, Abeer, Alessandretti, Laura, Kandler, Anne, Pastor-Satorras, Romualdo, Baronchelli, Andrea, 2017. Evolutionary dynamics of the cryptocurrency market. R. Soc. Open Sci. 4 170623. https://arxiv.org/abs/1705.05334.

Fama, E., 1970. Efficient capital markets: a review of theory and empirical evidence. J. Finance 25, 383-417.

Greene, M.T., Fielitz, B.D., 1977. Long-term dependence in common stock returns. J. Financ. Econ. 4, 339-349.

Halaburda, M.T., Gandal, Neil, 2014. Competition in the Cryptocurrency Market. NET Institute Working Paper No. 14-17. (Available at SSRN). https://ssrn.com/ abstract $=2506463$ or https://doi.org/10.2139/ssrn. 2506463 .

Hurst, H., 1951. Long-term storage of reservoirs. Trans. Am. Soc. Civil Eng. 116 (1), 770-799.

Kurihara, Yutaka, Fukushima, Akio, 2017. The market efficiency of bitcoin: a weekly anomaly perspective. J. Appl. Finance Bank. 7 (3), 57-64.

Lo, A.W., 1991. Long-term memory in stock market prices. Econometrica 59, 1279-1313.

Mynhardt, R.H., Plastun, A., Makarenko, I., 2014. Behavior of financial markets efficiency during the financial market crisis: 2007-2009. Corp. Ownersh. Control 11 (2), 473-488.

Phillips, P.C., Shimotsu, K., 2005. Exact local Whittle estimation of fractional integration. Ann. Stat. 33, $1890-1933$.

Robinson, P.M., 1994. Efficient tests of nonstationary hypotheses. J. Am. Stat. Assoc. 89, 1420-1437.

Robinson, P.M., 1995. Gaussian semi-parametric estimation of long range dependence. Ann. Stat. 23, 1630-1661.

Urquhart, A., 2016. The inefficiency of bitcoin. Econ. Lett. 148, 80-82.

Velasco, C., 1999. Gaussian semiparametric estimation of nonstationary time series. J. Time Series Anal. 20, 87-127.

\footnotetext{
${ }^{1}$ The choice of $\mathrm{m}$ is important since there is a trade-off between bias and variance that affects the estimates of $\mathrm{d}$.
} 